\title{
Understanding the Workflow of Home Health Care for Patients with Heart Failure: Challenges and Opportunities
}

\author{
Madeline R. Sterling, MD, MPH, MS' , Nicola Dell, $P h D^{2}$, Benedetta Piantella, $M S^{3}$, \\ Jacklyn Cho, $B S^{7}$, Harveen Kaur, $\mathrm{MPH}^{4}$, Emily Tseng, $\mathrm{MS}^{2}$, Fabian Okeke, $\mathrm{MS}^{2}$, \\ Mikaela Brown, BA ${ }^{2}$, Peggy B. K. Leung, MD' , Ariel F. Silva, NP' , Amy L. Shaw, MD', and \\ Lisa M. Kern, MD, MPH
}

'Department of Medicine, Division of General Internal Medicine, Weill Cornell Medicine, New York, NY, United States; ${ }^{2}$ Cornell Tech, New York, NY, USA; ${ }^{3}$ New York University, New York, NY, USA; ${ }^{4}$ Hackensack Meridan Health, Hackensack, NJ, USA.

\begin{abstract}
BACKGROUND: Readmission rates are high among heart failure (HF) patients who require home health care (HHC) after hospitalization. Although HF patients who require HHC are often sicker than those who do not, HHC delivery itself may also be suboptimal.
\end{abstract}

OBJECTIVE: We aimed to describe the workflow of HHC among adults discharged home after a HF hospitalization, including the roles of various stakeholders, and to determine where along these workflow challenges and opportunities for improvement exist.

DESIGN AND PARTICIPANTS: In this qualitative study, we used purposeful sampling to approach and recruit a variety of key stakeholders including home health aides, nurses, HF patients, family caregivers, physicians, social workers, home care agency leaders, and policy experts. The study took place in New York, NY, from March to October 2018.

APPROACH: Using a semi-structured topic guide, we elicited participants' experiences with $\mathrm{HHC}$ in $\mathrm{HF}$ through a combination of one-on-one interviews and focus groups. Data were recorded, transcribed, and analyzed thematically. We also asked selected participants to depict in a drawing their understanding of HHC workflow after hospitalization for HF patients. We synthesized the drawings into a final image.

KEY RESULTS: Study participants $(N=80)$ described $\mathrm{HHC}$ for $\mathrm{HF}$ patients occurring in 6 steps, with home health aides playing a main role: (1) transitioning from hospital to home; (2) recognizing clinical changes; (3) making decisions; (4) managing symptoms; (5) asking for help; and (6) calling 911. Participants identified challenges and opportunities for improvement for each step.

CONCLUSIONS: Our findings suggest that $\mathrm{HHC}$ for $\mathrm{HF}$ patients occurs in discrete steps, each with different challenges. Rather than a one-size-fits-all approach, various interventions may be required to optimize HHC delivery for $\mathrm{HF}$ patients in the post-discharge period.

KEY WORDS: home health care; heart failure; qualitative research; health services research.

Electronic supplementary material The online version of this article (https://doi.org/10.1007/s11606-020-05675-8) contains supplementary material which is available to authorized users.

Presentations This study was presented at the Society of General Internal Medicine Annual Meeting on May 11, 2019, in Washington, D.C., as a poster presentation.

Published online February 5, 2020
J Gen Intern Med 35(6): 1721-9

DOI: $10.1007 / \mathrm{s} 11606-020-05675-8$

(C) Society of General Internal Medicine 2020

\section{BACKGROUND}

Reducing hospital readmissions for patients with heart failure (HF) is a national priority for patients and payers. $^{1,2}$ Yet despite national efforts to reduce readmissions (including financial penalties from Medicare), rates of readmission remain relatively high. ${ }^{3}$ More than $20 \%$ of Medicare beneficiaries hospitalized for $\mathrm{HF}$ are readmitted within 30 days, and $50 \%$ are readmitted within 6 months. ${ }^{4-6}$ Readmission rates among patients who receive home health care (HHC) after a HF hospitalization are particularly high. ${ }^{7-11} \mathrm{HHC}$, which offers skilled nursing care; physical, occupational, and speech therapy; social work; and care from home health aides, is increasingly used by Medicare beneficiaries over the last decade, ${ }^{12-14}$ especially among adults with HF. ${ }^{15}$ In fact, $25 \%$ of patients discharged home after a HF hospitalization receive $\mathrm{HHC}$, a rate that exceeds other conditions for which patients are hospitalized. ${ }^{13}$

$\mathrm{HF}$ patients receiving $\mathrm{HHC}$ in the post-discharge period may have high readmission rates for several reasons. First, they tend to be older and sicker with more caregiving needs than HF patients not receiving HHC. ${ }^{14,16-18}$ Second, as recent studies have shown, HHC itself has not been optimized, with care poorly coordinated across various providers and home care agencies. ${ }^{19-23}$ While illuminating, these studies have not articulated the workflow of HHC, which has made it challenging to identify opportunities for improvement. Notably, the perspectives of home health aides - who are often the minuteto-minute observers of HF patients in the home after discharge-have been underrepresented in research. ${ }^{18,24} \mathrm{Ad}$ ditionally, while a growing body of literature describes the perspectives of patients and family caregivers, few studies have analyzed these perspectives alongside those of other stakeholders. $^{25-28}$ A better understanding of how HHC works, as well as the perspectives of those involved in its delivery, are needed to pinpoint opportunities for improvement. 
To address these gaps, we sought to (1) articulate the workflow of HHC among adults discharged home after a HF hospitalization, including the roles of various stakeholders; (2) determine where along these workflow challenges and barriers exist; and (3) identify opportunities to improve HHC delivery for HF patients.

\section{METHODS}

\section{Setting and Sampling}

This qualitative study was conducted from March to September 2018 in New York, NY. In order to achieve broad perspectives, we used purposeful sampling to target and recruit key stakeholders. ${ }^{29}$ Stakeholders were identified using a conceptual model that depicts HHC delivery for HF patients (Fig. 1). ${ }^{24}$ Thus, ten stakeholder groups were included: HF patients, family caregivers, home care agency leaders and staff, home health aides, visiting nurses, physicians, hospital social workers and care coordinators, home care worker union leaders, and policy experts. Because the focus of this study is on HHC post-discharge, we only recruited home health aides, and not home attendants or personal care aides, which tend to provide long-term care for HF patients.]

One researcher (MRS) recruited participants via direct outreach to leaders at targeted organizations. HF patients and family caregivers of HF patients were recruited from Weill Cornell Medicine internal medicine and geriatrics practices, in collaboration with two other ongoing studies about caregiving. All participants provided verbal or written consent to record the interview. Modest financial incentives were provided to patients, home health aides, and nurses, but not to other stakeholders. The study was approved by the Institutional Review Board of Weill Cornell Medicine and adhered to the Consolidated Criteria for Reporting Qualitative Research. ${ }^{30}$

\section{Data Collection}

Four researchers (MRS, BP, JC, ALS) trained in qualitative methods conducted the interviews using a semi-structured topic guide, which was informed by current literature and our prior work on home health aides, HF patients, and family caregivers. ${ }^{24,} 31,32$ Questions were adapted for each stakeholder group but broadly focused on (1) how HHC is obtained and delivered after a HF hospitalization to patients; (2) who does what in HHC delivery; and (3) challenges and opportunities with $\mathrm{HHC}$ in the post-discharge period for HF patients (Appendix Table 4). For participant convenience, we conducted interviews in a one-on-one fashion or in a focus group. We collected a limited amount of demographic data.

Beyond the interview, 14 participants who represented different stakeholder groups were asked to draw on paper their understanding of HHC delivery for adults discharged home after a HF hospitalization. Drawing has been used as a data collection tool in previous studies, particularly when the goal is to investigate a complex situation with multiple stakeholders. ${ }^{33,}{ }^{34}$ The decision to supplement interviews with drawing emerged when during the first several interviews, some participants explained that their description of HHC workflow would be enhanced if they could visually depict the process.

\section{Data Analysis}

Interviews were recorded and professionally transcribed. Two members of the research team (MRS, ND) led the analysis, and 3 other members (JC, BP, HK) coded the data. Data were analyzed thematically, an approach that has been widely used in health-related research when a conceptual model already exists. ${ }^{35,}{ }^{36}$ Since the framework used in our prior study focused on home health aides who cared for HF patients and not other stakeholders, we took a flexible analytic approach, using established codes when appropriate, but also open coding when we came across new concepts. ${ }^{37,} 38$

Coding occurred alongside interviews. Three members of the research team (JC, BP, HK) independently reviewed the first 5 transcripts. Under the guidance of a fourth author (MRS), a codebook was developed until consensus was reached on code definitions. The codebook was applied to the remaining transcripts and subsequent transcripts were independently coded by the three coders (JC, BP, HK), who met (along with author MRS) every fifth transcript to reconcile coding differences. The final codebook is available in Appendix Table 3. Because similar codes emerged across stakeholder groups, we applied the same codebook to all interviews and focus groups. Data collection ended when data saturation was achieved, or the point at which no new themes were identified. ${ }^{39}$ Themes were discussed among the study team until consensus was reached and were reviewed with a senior investigator (LMK). NVivo software was used to manage the data. Participant drawings were analyzed and synthesized by one author (MRS), who developed a final summary drawing. As in other studies, a subset of participants were asked to review the final drawing for face and content validity, accuracy, and completeness. ${ }^{20}$ The diagram was revised based on their feedback.

\section{RESULTS}

Eighty participants were interviewed (Table 1). The home health aides, nurses, agency leaders, and agency staff were from 9 unique home care agencies in New York, NY. Agencies were diverse in size (small, medium, and large) and location. Physicians, social workers, care coordinators, HF patients, and family caregivers were recruited from a large, urban academic medical center. HF patients were on average 73 years of age (SD 4 years) and $80 \%$ were women; family caregivers were on average 63 years of age (SD 12 years) and all were women. Interviews lasted between 30 and $60 \mathrm{~min}$. 


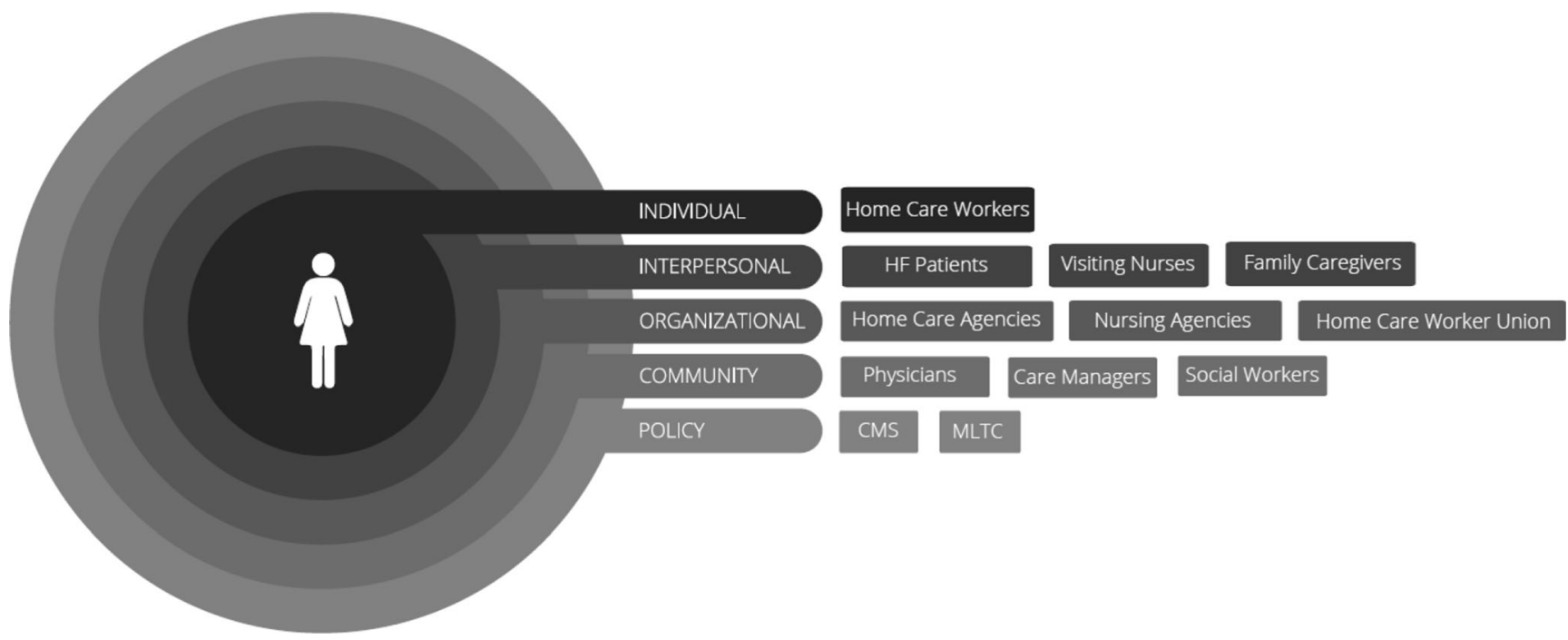

Figure 1 Conceptual model of factors influencing the delivery of care by home health aides to adults with heart failure. Figure reproduced with permission from Sterling et al. ${ }^{24}$

\section{Intended Workflow of Home Healthcare for Heart Failure Patients in the Post-discharge Period}

Participants identified 6 main steps in the workflow of HHC for HF patients, with home health aides playing a main role, as described below and in Figure 2.]

Step 1: Transitioning from Hospital to Home. Following the determination by the inpatient medical team that skilled home care is required, patients are discharged home with $\mathrm{HHC}$ services. A visiting nurse performs an assessment and drafts a care plan, later reviewed and approved by the patient's physician, which guides home care. A home health aide may be assigned to assist the patient with personal and medical care. After this initial assessment, visiting nurses conduct intermittent assessments. Home health aides may be in the home multiple days a week. The degree to which home health aides are involved varies with patient preference and the involvement of family caregivers.

Step 2: Recognizing Clinical Changes. Home health aides may observe shortness of breath, leg swelling, fatigue, chest pain, or other symptoms. Family caregivers may also observe these symptoms.

Step 3: Making Decisions. Once a clinical change is observed, home health aides decide what to do about it, guided by the care plan.

Step 4: Managing Symptoms. Home health aides attempt to manage patients' symptoms at home when they perceive clinical changes to be of low risk and the care plan outlines the appropriate response.

Step 5: Asking for Help. When the clinical changes observed are more severe or home health aides are unsure of what to do, they call their home care agency for guidance. The agency coordinator triages the problem, often connecting aides to their supervising nurse.

Step 6: Calling 911. When clinical changes are perceived to be of high risk, home health aides and/or family members may call 911. Uncertainty about symptom management may also prompt 911 calls. Attempts to reach patients' doctors are sometimes done in parallel.

\section{Challenges and Opportunities with Workflow of Home Health care in Heart Failure}

Participants described several challenges with these 6 steps of HHC workflow, including opportunities to address each of them. These are presented below with illustrative quotations and are summarized in Table 2.

Step 1: Transitioning from Hospital to Home. Challenge \#1. Many participants reported that initiating HHC felt like a "black box"; the logistics of HHC were confusing and the roles of home health aides and agency nurses were unclear to physicians, patients, and family members alike. One physician remarked,

I don't have a clear grasp of how the system works. I don't know exactly where the aides are coming from. The whole process is confusing.

Opportunity \#1. To address the confusion surrounding HHC, instructing stakeholders on the principles and optimal workflow of HHC delivery prior to hospital discharge would be helpful. For example, many patients and family caregivers explained that a training session or handout on the process could be distributed and reviewed ahead of the patients' discharge, which would fill knowledge gaps. Notably, 
Table 1 Study Participants and Data Collection

\begin{tabular}{|c|c|c|c|}
\hline $\begin{array}{l}\text { Stakeholder } \\
\text { level }\end{array}$ & $\begin{array}{l}\text { Stakeholder } \\
\text { participants }\end{array}$ & $N^{*}$ & $\begin{array}{l}\text { Type of data } \\
\text { collection }\end{array}$ \\
\hline Individual & Heart failure patients & 8 & $\begin{array}{l}\text { Individual } \\
\text { interview }\end{array}$ \\
\hline \multirow{3}{*}{ Interpersonal } & Home health aides & 8 & 2 focus groups \\
\hline & $\begin{array}{l}\text { Home care agency } \\
\text { nurses* }\end{array}$ & 7 & $\begin{array}{l}\text { Individual } \\
\text { interviews }\end{array}$ \\
\hline & Family caregivers & 3 & $\begin{array}{l}\text { Individual } \\
\text { interviews }\end{array}$ \\
\hline \multirow[t]{4}{*}{ Organizational } & $\begin{array}{l}\text { Home care agency } \\
\text { leaders }\end{array}$ & 13 & $\begin{array}{l}\text { Individual } \\
\text { interviews }\end{array}$ \\
\hline & $\begin{array}{l}\text { Home care agency } \\
\text { staff }^{\dagger}\end{array}$ & 23 & 5 focus groups \\
\hline & Nursing agency leaders & 2 & $\begin{array}{l}\text { Individual } \\
\text { interviews }\end{array}$ \\
\hline & $\begin{array}{l}\text { Union leadership and } \\
\text { staff }\end{array}$ & 4 & $\begin{array}{l}\text { Individual } \\
\text { interviews }\end{array}$ \\
\hline Community & $\begin{array}{l}\text { Physicians, social } \\
\text { workers, and care } \\
\text { coordinators }\end{array}$ & 7 & $\begin{array}{l}\text { Individual } \\
\text { interviews }\end{array}$ \\
\hline Policy & Nonprofit organizations & 5 & $\begin{array}{l}1 \text { focus group and } \\
\text { individual } \\
\text { interviews }\end{array}$ \\
\hline
\end{tabular}

*Home care agency nurses included nurses employed by home care agencies who are currently providing clinical care (RNs, LPNS)

tHome care agency staff included non-clinical staff members at home care agencies (administrators, care managers, operations staff)

$\neq$ Eighty participants were interviewed

hospital providers also seemed to want more information on the process.

The medical people don't understand who the players are when patients are going home... I often say to myself, could we all have a half-semester course on this home care stuff? (laughing) (Care coordinator)
Table 2 Challenges and Opportunities with of Home Health care Workflow Among Heart Failure Patients

\begin{tabular}{|c|c|c|}
\hline $\begin{array}{l}\text { HHC workflow } \\
\text { step }\end{array}$ & Challenges* & Opportunities* \\
\hline $\begin{array}{l}\text { Step 1: } \\
\text { Transitioning from } \\
\text { hospital to home }\end{array}$ & $\begin{array}{l}\text { HHC is confusing } \\
\text { Lack of care } \\
\text { coordination } \\
\text { Poor exchange of } \\
\text { information }\end{array}$ & $\begin{array}{l}\text { Education on HHC } \\
\text { Huddles and orientation } \\
\text { sessions } \\
\text { Formal handoff } \\
\text { processes }\end{array}$ \\
\hline $\begin{array}{l}\text { Step 2: } \\
\text { Recognizing } \\
\text { clinical changes } \\
\text { Step 3: Making } \\
\text { decisions } \\
\text { Step 4: Managing } \\
\text { symptoms }\end{array}$ & $\begin{array}{l}\text { Lack of HF training } \\
\text { Insufficient care } \\
\text { plan detail }\end{array}$ & $\begin{array}{l}\text { Training on HF for } \\
\text { home health aides } \\
\text { Care plan tailored to HF }\end{array}$ \\
\hline $\begin{array}{l}\text { Step 5: Asking for } \\
\text { help }\end{array}$ & $\begin{array}{l}\text { Difficulty reaching } \\
\text { supervisors } \\
\text { Lack of knowledge } \\
\text { of whom to call on } \\
\text { the medical team }\end{array}$ & $\begin{array}{l}\text { Use of technology to } \\
\text { improve call chain } \\
\text { Identification of point } \\
\text { person on medical and } \\
\text { home care teams }\end{array}$ \\
\hline Step 6: Calling 911 & $\begin{array}{l}\text { High frequency of } \\
911 \text { calls }\end{array}$ & $\begin{array}{l}\text { Addressing other } \\
\text { challenges may decrease } \\
\text { the frequency of } 911 \mathrm{~s}\end{array}$ \\
\hline
\end{tabular}

HHC home health care, HF heart failure

*Within each step, specific challenges correspond to specific opportunities across rows

There are many different nurses and doctors involved [in patient care]...but the aides are not involved in the discharge process and physicians are not involved in home care. It's not coordinated. (Clinical supervisor, home care agency)

Poor communication between hospital physicians, agency staff, and home health aides compounded this lack of coordination.

There is really poor communication between us, the agency nurse, the family, and the worker... lots of

Challenge \#2. There was little coordination between the HF patients' inpatient medical teams and those providing care at home.



Figure 2 Home healthcare workflow for heart failure patients in the post-discharge period. The intended workflow of home healthcare for heart failure patients in the post-discharge period. The 6 main steps in the workflow are highlighted with red numbers and correspond to individual steps, as follows. Not all steps are necessarily used for any given patient. (1) Transition from hospital to home; (2) clinical changes; (3) decision making; (4) managing the symptoms; (5) asking for help; (6) calling 911. 
people involved and none of us are talking. (Staff member, home care agency)

Opportunity\#2. To address issues with care coordination and communication, participants suggested that there be more continuity between inpatient staff and HHC professionals. Participants suggested establishing an inperson huddle, which could include a home care agency staff member, in the hospital prior to discharge. Patients and agency staff also suggested an in-home orientation at the beginning of HHC episodes, as stated by a patient:

There's no orientation to what is happening. A nurse shows up from here and the aide from there... I mean, you need everyone in person for a discussion or at least a call. Everybody has to hear the same conversation to coordinate the care.

Another suggestion was to establish a formalized handoff process between multiple aides caring for the same HF patient.

Challenge \#3. Another challenge with the transition from hospital to HHC was poor exchange of patient information across care settings. For example, the discharge summary from the HF hospitalization rarely made it into the hands of those providing home care.

We send a discharge summary to the home care agency. We work to make the safest plan possible, but it's unlikely the worker ever sees this information. (Social worker)

Participants also said that home health aides were rarely informed of the discharge diagnosis itself (e.g., HF) at the beginning of the HHC episode. This frustrated agency staff, home health aides, and some patients.

I think the aide should have access to my medical chart.

... Shouldn't they know what's going on with me? (Patient)

Privacy regulations (e.g., HIPAA) were cited as the main reason why information about the patient was not provided to aides, although some participants debated the merits of this policy, as expressed here:

[B]ecause of HIPAA, they can't be informed of certain things. It's unclear why they aren't considered healthcare professionals, since they are the ones doing the caring. (Agency staff member)
Opportunity \#3. To address problems with information exchange, some participants suggested formal processes to ensure communication between inpatient teams (who author the discharge summary) and agency nurses (who draft the care plan). Improving home health aides' access to patients' medical history, however, would require policy changes at the agency level.

...HIPAA is a tough nut to crack because all the agencies are worried about liability. (Union leader)

\section{Steps 2, 3, and 4: Recognizing Clinical Changes, Making} Decisions, and Managing Symptoms. Challenge \#1. Home health aides struggled with perceiving clinical changes among HF patients, such as new swelling, worsened fatigue, or new cognitive impairment. Many explained that this was in part because they have not received HF-specific resources or training on HF maintenance or HF management including symptom exacerbations.

It's really hard to know what to do if you haven't been taught what to do for these patients. (Home health aide)

Opportunity \#1. To address this, home health aides, nurses, and agency leaders wanted classroom-based training on HF for home health aides. Many felt that learning about the signs and symptoms of HF and how to manage patients' clinical changes would be important.

What we really need is training on this disease for aides. We need patient-centered, case-based learning. Each patient is different and they need to know what to do. (Nurse)

In addition to in-person training, technology was cited as a mechanism to improve clinical decision making in the home.

...Tech-based tools can guide home health aides - help them with care tasks and give them as much information about providing care for patients. (CEO, home care agency)

Challenge \#2. Many participants found the care plan inadequate to guide care for HF patients. In some instances, the plan did not contain enough details about HF to guide the aide. In others, the plan did not state that the patient had HF, which created additional challenges for the aide. 
There's definitely nothing an aide can do to help them figure out (from the care plan) that this is HF or how to handle clinical situations. (Nursing leader)

Opportunity \#2. Agency staff members and home health aides suggested that an improved care plan for HF should include specific information about HF symptoms, medications, and which doctor to call with questions.

Step 5: Asking for Help. Challenge \#1. The process of asking for clinical help in the home was problematic. Although home health aides are instructed to call their agency for guidance on how to manage HF patients' symptoms, many reported that they often could not get in touch with the nurse in a timely fashion. One nurse explained that a call chain is often triggered:

The aide observes a change in the patient's condition. She calls a center, who sends the message to the agency coordinator. The coordinator sends it to the managed long-term care plan contractor, who sends it to a nurse $\ldots$ all of this takes a long time.

Opportunity \#1. Rather than relying on a phone-based system, participants suggested that technology - specifically, text messaging - could improve the ability of home health aides to reach their supervising nurses. Enthusiasm for this was seen among aides and some agency leaders who reported already exploring this as a solution.

...We did a pilot where a tablet was placed in the home and an alert went to one of the clinical managers that we had at the agency. It went really well- the workers loved it. (CEO, home care agency)

Challenge \#2. In addition to not being able to reach each other, home health aides and nurses reported difficulty contacting the medical team who cared for the HF patient in the hospital. Physicians also acknowledged this issue:

There is a lot of confusion about who patients should call once they're home. Often they call the primary care doctor, but get an answering service and are told to go to the ER. If they call the hospital they are told the same thing. This leads to mass confusion.
This issue also came up when HF patients needed to be readmitted to the hospital and hospital providers tried to get in touch with HHC providers.

...When the patient is readmitted, we have to call this elaborate chain of people to even figure out what happened in the home. It's all just sort of crazy. (social worker)

Opportunity \#2. Participants suggested that this problem could be addressed if a point person was identified prior to discharge that the home health aide or visiting nurse could call, and vice versa, when clinical issues with HF patients arise in the home.

Step 6: Calling 911. Challenge \#1. Nearly all participants remarked that calling 911 for HF patients receiving HHC occurs frequently, especially when clinical changes are perceived to be worrisome.

When a patient is having airway issues, naturally, that's immediately referred to 911 . (Nurse)

Sometimes, however, 911 calls were made due to the ineffective call chain described in Step 5, Challenge 1.

We have 1 nurse for all of our aides, so it's tough. Aides can try to report symptoms, but it's hard to get through. Ultimately, if the patient doesn't have a doctor's appointment the next day, the aide is likely to call 911 . (Clinical supervisor, home care agency)

Participants remarked that calling 911 usually led to the patient, the home health aide, and sometimes the family member going to the hospital.

Opportunity \#1. Nearly all stakeholders were eager to reduce unnecessary 911 calls. Agency leaders explained that this was especially important because Medicare now imposes financial penalties on home care agencies for avoidable hospitalizations. Opportunities to reduce these calls involved addressing several of the challenges upstream of the 911 call and potentially leveraging the role of the home health aide.

\section{DISCUSSION}

Participants articulated that the workflow of HHC for HF patients following discharge ideally occurs in 6 main steps: (1) transitioning from hospital to home, (2) recognizing clinical changes, (3) making decisions, (4) managing symptoms, (5) asking for help, and (6) calling 911. In reality, we found 
several challenges to each of these components. Our findings suggest that a variety of different interventions will be required to optimize HHC delivery for HF patients in the postdischarge period.

Poor communication affected almost every step of HHC workflow and nearly all stakeholder groups in this study. This finding expands the current HF and home healthcare literature, which has primarily focused on gaps in communication between inpatient physicians and home care nurses. ${ }^{19-21,23,40,41}$ Four examples of poor communication from this study are worth highlighting. First, pertinent medical information from the HF hospitalization did not reliably reach the home care agency responsible for the HF patients' care at home. This frustrated hospital providers, who tried to ensure a safe discharge, and agency nurses and home health aides, who lacked information for patient care. A second breakdown in communication was the uncertainty surrounding who on the medical team should be called with clinical questions in the home. While this issue has been previously described among HHC nurses, ${ }^{19}$ we found that home health aides, patients, and family members were also unsure of who to call. Similarly, hospital staff did not know who to call at the home care agency for sign-out when HF patients were readmitted. Third, although home health aides were instructed to call the nurse at their agency for clinical guidance, this line of communication was inefficient, especially when HF patients were symptomatic. Frustrated and isolated, many aides called 911 instead. Finally, communication gaps were present when multiple home health aides cared for the same HF patient. Taken together, communication challenges affected several stakeholder groups and imposed significant problems for HHC workflow.

Another key finding of our study was the centrality of the home health aide to HHC workflow for HF patients. Prior quantitative and qualitative studies have generally focused on nurses, agency staff, and other health professionals, including physicians, physical therapists, and care transition coaches. ${ }^{22}$, 23, 40, 42 Our inclusion of home health aides was prompted by work in the geriatrics and palliative care literature that has described home health aides as patients' "eyes and ears" in the home. ${ }^{43,}{ }^{44}$ Additionally, our recent work and our previously developed conceptual model on HHC delivery demonstrates that home health aides are deeply involved in many aspects of HF patients' self-care. ${ }^{24}$ Here, we found that in addition to assisting with personal and medical care, home health aides observed and triaged HF patients' clinical changes. However, home health aides face many challenges in providing care, including not being told that patients have HF, not always being able to perceive clinical changes, and not being able to reliably connect with nurses when they required clinical guidance. Finally, unlike other studies, we found that the home health aide - not the nurse, doctor, or patient — calls 911 frequently, which has numerous downstream consequences for patients, families, agencies, and hospitals.
Given the increasing prevalence of HHC among adults discharged home after HF hospitalizations, we found it striking that physicians, medical staff, patients, and family caregivers were confused by HHC itself. The US population is rapidly aging, and older adults increasingly rely on $\mathrm{HHC}$ for post-acute and long-term care. ${ }^{45}$, ${ }^{46} \mathrm{HF}$ patients, who often have comorbidities ${ }^{47}$ and functional and cognitive deficits, ${ }^{48-50}$ use HHC more frequently than other Medicare beneficiaries after hospitalization. ${ }^{14}$ Yet, we found that many regard $\mathrm{HHC}$ as a "black box," confusing to initiate and even more baffling to coordinate and understand. Although confusion about HHC has been documented in the lay press, ${ }^{51}$ few studies have investigated this phenomenon. ${ }^{52}$ Quantitative studies are needed to determine the prevalence of providers' and caregivers' gaps in HHC knowledge and their educational needs on this topic.

\section{Strengths and Limitations}

Our study is the first to examine HHC workflow in HF with this breadth of stakeholder engagement. Recruitment of diverse stakeholders was purposeful and was guided by a conceptual model. Data were collected and analyzed using a rigorous, thematic approach. Finally, we incorporated drawing analysis which enabled us to capture complex and interrelated processes that may not have emerged through standard interviews alone. We also note a few limitations. First, we recruited home health aides' and home care agencies' leaders from licensed and unionized agencies, which limits our ability to generalize our findings to privately employed or nonunionized populations. Second, because our focus was the post-discharge period, we recruited home health aides who provide post-acute care and did not recruit other paid aides who contribute to HF care in the home, such as personal and home care attendants. As such, we may be missing their perspectives in this study. Finally, this study was conducted in New York, NY, so findings may not apply to small cities or rural areas.

\section{IMPLICATIONS}

Despite these limitations, our study offers a roadmap for the development of interventions to optimize healthcare delivery for adults who receive $\mathrm{HHC}$ after a $\mathrm{HF}$ hospitalization. It is likely that several types of interventions will be needed. Interventions that aim to improve communication and handoffs in HHC, both between home and hospital providers and between home health aides and nurses caring for the same patient, are warranted. Additionally, educating and training home health aides to recognize the signs and symptoms of HF is critical. Indeed, similar training programs already exist for home 
health aides caring for adults with dementia and diabetes. ${ }^{53-55}$ Finally, raising awareness of $\mathrm{HHC}$ and the stakeholders involved is needed.

Our findings also have important policy implications. The Centers for Medicare and Medicaid Services announced the launch of a mandatory national Home Health Value-Based Purchasing model (HHVBP) in 9 states in 2016. ${ }^{56}$ Starting in 2018, home care agencies have been either financially rewarded or penalized based on their performance on quality measures, including unplanned readmissions and emergency department use. $^{40,57-59}$ As demonstrated by our findings, optimizing $\mathrm{HHC}$ will be critical for agencies to thrive under HHVBP. For example, in order to reduce emergency department use, home health aides will need additional HF training, more hands-on support, and more effective means to reach their supervisors. ${ }^{60}$

\section{CONCLUSION}

Our study offers a comprehensive understanding of how HHC is delivered to HF patients in the post-discharge period. In contrast to prior studies, we found that for HF patients, HHC occurs in a series of discrete steps, each plagued with challenges. Thus, in order to optimize HHC for HF patients and potentially reduce readmissions, a variety of interventions will be required. Addressing opportunities identified by these stakeholders is aligned with and required by new federal reimbursement policies. Improving care for patients with HF who require $\mathrm{HHC}$ will benefit patients, families, providers, and payers alike.

Acknowledgments: We would like to thank all of the participants who gave their time and offered their insights.

Corresponding Author: Madeline R. Sterling, MD, MPH, MS; Department of Medicine, Division of General Internal Medicine Weill Cornell Medicine, 420 E 70th Street, New York, NY 10021, United States (e-mail: mrs9012@med.cornell.edu).

Funding Information This study was supported by the 2018 Founders Grant from the Society of General Internal Medicine and an Engaged Opportunity Grant from Cornell University (EOG 18.015). The views expressed here do not reflect those of the Society of General Internal Medicine or Cornell University. Dr. Sterling and Dr. Dell are currently supported, in part, by the Robert Wood Johnson Foundation (Grant No. 76487). The views expressed here do not reflect those of the foundation.

\section{Compliance with Ethical Standards:}

All participants provided verbal or written consent to record the interview. The study was approved by the Institutional Review Board of Weill Cornell Medicine and adhered to the Consolidated Criteria for Reporting Qualitative Research. ${ }^{30}$

Conflict of Interest: The authors declare that they do not have a conflict of interest.

\section{REFERENCES}

1. Mozaffarian D, Benjamin EJ, Go AS, et al. Heart Disease and Stroke Statistics-2016 Update: A Report From the American Heart Association. Circulation. 2016;133(4):e38-360.

2. Gheorghiade M, Vaduganathan M, Fonarow GC, Bonow RO. Rehospitalization for heart failure: problems and perspectives. J Am Coll Cardiol. 2013;61(4):391-403.

3. Blecker S, Herrin J, Li L, Yu H, Grady JN, Horwitz LI. Trends in Hospital Readmission of Medicare-Covered Patients With Heart Failure. $J$ Am Coll Cardiol. 2019;73(9):1004-1012.

4. Jencks SF, Williams MV, Coleman EA. Rehospitalizations among patients in the Medicare fee-for-service program. $N$ Engl $J$ Med. 2009;360(14):1418-1428.

5. Chang PP, Wruck LM, Shahar E, et al. Trends in Hospitalizations and Survival of Acute Decompensated Heart Failure in Four US Communities (2005-2014): ARIC Study Community Surveillance. Circulation. 2018;138(1):12-24.

6. Cheng RK, Cox M, Neely ML, et al. Outcomes in patients with heart failure with preserved, borderline, and reduced ejection fraction in the Medicare population. Am Heart J. 2014; 168(5):721-730.

7. Madigan EA, Gordon NH, Fortinsky RH, Koroukian SM, Pina I, Riggs JS. Rehospitalization in a national population of home health care patients with heart failure. Health Serv Res. 2012;47(6):2316-2338.

8. Madigan EA. People with heart failure and home health care resource use and outcomes. J Clin Nurs. 2008;17(7b):253-259.

9. Arundel C, Sheriff H, Bearden DM, et al. Discharge home health services referral and 30-day all-cause readmission in older adults with heart failure. Arch Med Sci. 2018;14(5):995-1002.

10. Hoskins LM, Walton-Moss B, Clark HM, Schroeder MA, Thiel L, Sr. Predictors of hospital readmission among the elderly with congestive heart failure. Home Healthc Nurse. 1999;17(6):373-381.

11. Murtaugh CM, Deb P, Zhu C, et al. Reducing Readmissions among Heart Failure Patients Discharged to Home Health Care: Effectiveness of Early and Intensive Nursing Services and Early Physician Follow-Up. Health Serv Res. 2017;52(4): 1445-1472.

12. Bueno H, Ross JS, Wang Y, et al. Trends in length of stay and short-term outcomes among Medicare patients hospitalized for heart failure, 19932006. Jama. 2010;303(21):2141-2147.

13. Jones CD, Ginde AA, Burke RE, Wald HL, Masoudi FA, Boxer RS. Increasing Home Healthcare Referrals upon Discharge from U.S. Hospitals: 2001-2012. J Am Geriatr Soc. 2015;63(6):1265-1266.

14. Jones CD, Wald HL, Boxer RS, et al. Characteristics Associated with Home Health Care Referrals at Hospital Discharge: Results from the 2012 National Inpatient Sample. Health Serv Res. 2017;52(2):879-894.

15. The Centers for Medicare \& Medicaid Services Takes Action to Modernize Medicare Home Health. 2018; https://www.cms.gov/newsroom/pressreleases/cms-takes-action-modernize-medicare-home-health. Accessed November 5, 2018, 2018.

16. Anderson MA, Pena RA, Helms LB. Home care utilization by congestive heart failure patients: a pilot study. Public Health Nurs. 1998;15(2):146162.

17. Moulton PJ, McGrane AM, Beck TL, Holland NL, Christopher MA. Utilization of Home Health Care Services by Elderly Patients with Heart Failure. 1998, 10(4): 66-73.

18. Sterling MR, Shaw AL, Leung PB, et al. Home care workers in heart failure: a systematic review. J Multidiscip Healthc. 2018;11:481-492.

19. Jones CD, Jones J, Richard A, et al. "Connecting the Dots": A Qualitative Study of Home Health Nurse Perspectives on Coordinating Care for Recently Discharged Patients. $J$ Gen Intern Med. 2017;32(10):1114-1121.

20. Nasarwanji M, Werner NE, Carl K, et al. Identifying Challenges Associated With the Care Transition Workflow From Hospital to Skilled Home Health Care: Perspectives of Home Health Care Agency Providers. Home health care services quarterly. 2015;34(3-4):185-203.

21. Press MJ, Gerber LM, Peng TR, et al. Postdischarge Communication Between Home Health Nurses and Physicians: Measurement, Quality, and Outcomes. J Am Geriatr Soc. 2015;63(7):1299-1305.

22. Beer JM, McBride SE, Mitzner TL, Rogers WA. Understanding Challenges in the Front Lines of Home Health Care: A Human-Systems Approach. Appl Ergon. 2014;45(6):1687-1699.

23. Squires A, Ridge L, Miner S, McDonald MV, Greenberg SA, Cortes T. Provider Perspectives of Medication Complexity in Home Health Care: A Qualitative Secondary Data Analysis. Medical care research and review : MCRR. 2019:1077558719828942. 
24. Sterling MR, Silva AF, Leung PBK, et al. "It's Like They Forget That the Word 'Health' Is in 'Home Health Aide": Understanding the Perspectives of Home Care Workers Who Care for Adults With Heart Failure. Journal of the American Heart Association. 2018;7(23):e010134.

25. Hwang B, Fleischmann KE, Howie-Esquivel J, Stotts NA, Dracup K. Caregiving for patients with heart failure: impact on patients' families. American journal of critical care : an official publication, American Association of Critical-Care Nurses. 2011;20(6):431-441; quiz 442.

26. Nicholas Dionne-Odom J, Hooker SA, Bekelman D, et al. Family caregiving for persons with heart failure at the intersection of heart failure and palliative care: a state-of-the-science review. Heart failure reviews. 2017.

27. Piamjariyakul U, Smith CE, Werkowitch M, Elyachar A. Part I: heart failure home management: patients, multidisciplinary health care professionals and family caregivers' perspectives. Applied nursing research : ANR. 2012;25(4):239-245.

28. Sterling MR, Shaw AL. Sharing the Care-A Patient and Her Caregivers. JAMA Intern Med. 2019. Sep 30. https://doi.org/10.1001/ jamainternmed.2019.4231.

29. Palinkas LA, Horwitz SM, Green CA, Wisdom JP, Duan N, Hoagwood K. Purposeful Sampling for Qualitative Data Collection and Analysis in Mixed Method Implementation Research. Administration and policy in mental health. 2015;42(5):533-544.

30. Tong A, Sainsbury P, Craig J. Consolidated criteria for reporting qualitative research (COREQ): a 32-item checklist for interviews and focus groups. Int $J$ Qual Health Care. 2007;19(6):349-357.

31. Sterling MR, Silva AF, Robbins L, Dargar SK, Schapira MM, Safford MM. Let's talk numbers: a qualitative study of community-dwelling US adults to understand the role of numeracy in the management of heart failure. BMJ Open. 2018;8(9):e023073.

32. Sims-Gould J, Byrne $\mathbf{K}$, Tong $\mathbf{C}$, Martin-Matthews A. Home support workers perceptions of family members of their older clients: a qualitative study. BMC geriatrics. 2015;15: 165 .

33. Zweifela C, Van Wezemaela J. Drawing as a qualitative research tool: an approach to field work from a social complexity perspective. Tracey Journal: Drawing Knowledge. 2012;5:1-16.

34. Mair M, Kierans C. Descriptions as data: Developing techniques to elicit descriptive materials in social research. J Visual Studies. 2007;22(2):120 136.

35. Lyons E, Coyle A, Terry G. Doing thematic analysis.: Sage; 2016.

36. Braun V, Clarke V. Using thematic analysis in psychology. Qualitative Research in Psychology. 2006;3(2):77-101.

37. Strauss C. Basics of Qualitative Research. Sage; 2015.

38. Fereday J, Muir-Cochrane E. Demonstrating rigor using thematic analysis: A hybrid approach of inductive and deductive coding and theme development. Vol 52006:80-92.

39. Hennink MM, Kaiser BN, Marconi VC. Code Saturation Versus Meaning Saturation: How Many Interviews Are Enough? Qual Health Res. 2017;27(4):591-608.

40. Jones CD, Bowles KH, Richard A, Boxer RS, Masoudi FA. High-Value Home Health Care for Patients With Heart Failure: An Opportunity to Optimize Transitions From Hospital to Home. Circ Cardiovasc Qual Outcomes. 2017;10(5).

41. Arbaje AI, Hughes A, Werner N, et al. Information management goals and process failures during home visits for middle-aged and older adults receiving skilled home healthcare services after hospital discharge: a multisite, qualitative study. BMJ Quality \& Safety. 2019;28(2):111-120.

42. Feltner C, Jones CD, Cene CW, et al. Transitional care interventions to prevent readmissions for persons with heart failure: a systematic review and meta-analysis. Ann Intern Med. 2014;160(11):774-784.
43. Lai D, Cloyes KG, Clayton MF, et al. WE'RE THE EYES AND THE EARS, BUT WE DON'T HAVE A VOICE: PERSPECTIVES OF HOSPICE AIDES. Journal of hospice and palliative nursing : JHPN : the official journal of the Hospice and Palliative Nurses Association. 2018;20(1):47-54.

44. Liken MA, King SK. Home health aide services: barriers perceived by dementia family caregivers. Home Healthc Nurse. 1995;13(6):60-68.

45. Landers S, Madigan E, Leff B, et al. The Future of Home Health Care: A Strategic Framework for Optimizing Value. Home Health Care Manag Pract. 2016;28(4):262-278.

46. Wang $\mathbf{Y}$, Leifheit-Limson EC, Fine $\mathbf{J}$, et al. National Trends and Geographic Variation in Availability of Home Health Care: 2002-2015. J Am Geriatr Soc. 2017;65(7):1434-1440.

47. Riegel B, Moser DK, Anker SD, et al. State of the science: promoting self-care in persons with heart failure: a scientific statement from the American Heart Association. Circulation. 2009;120(12):1141-1163.

48. Sterling MR, Jannat-Khah D, Bryan J, et al. The Prevalence of Cognitive Impairment Among Adults With Incident Heart Failure: The "Reasons for Geographic and Racial Differences in Stroke" (REGARDS) Study. J Card Fail. 2019;25(2):130-136.

49. Sterling MR, Safford MM, Goggins K, et al. Numeracy, Health Literacy, Cognition, and 30-Day Readmissions among Patients with Heart Failure. $J$ Hosp Med. 2018;13(3):145-151.

50. Sterling MR, Silva AF, Charlson ME. Sensory Impairments in Heart Failure-Are We Missing the Basics?: A Teachable MomentSensory Impairments in Heart FailureSensory Impairments in Heart Failure. JAMA Internal Medicine. 2018;178(6):843-844.

51. Graham J. Why confusion leads seniors to turn down home health care. 2017; https://www.cnn.com/2017/06/23/health/seniors-refuse-homehealth-care-partner/index.html.

52. Romagnoli KM, Handler SM, Hochheiser H. Home Care: More Than Just A Visiting Nurse. BMJ Qual Saf. 2013;22(12):972-974.

53. 1199SEIU Funds: Home Care Industry Education Fund. Last accessed October 12, 2019. Available at https://www.1199seiubenefits.org/homecare-ed-fund/.

54. Feldman PH, Ryvicker M, Evans LM, Barron Y. The Homecare Aide Workforce Initiative: Implementation and Outcomes. J Appl Gerontol. 2019;38(2):253-276.

55. Russell D, Mola A, Onorato N, et al. Preparing Home Health Aides to Serve as Health Coaches for Home Care Patients With Chronic Illness: Findings and Lessons Learned From a Mixed-Method Evaluation of Two Pilot Programs. Vol 292017:191-198.

56. The Centers for Medicare \& Medicaid Services. Home Health Value-Based Purchasing Model. 2019; https://innovation.cms.gov/initiatives/homehealth-value-based-purchasing-model. Accessed April 3, 2019.

57. The Centers for Medicare \& Medicaid Services. Hospital Compare. 2018; https://www.medicare.gov/hospitalcompare/search.html. Accessed June 21, 2018.

58. The Centers for Medicare \& Medicaid Services. Home Health Quality Reporting Program. 2018; https://www.cms.gov/Medicare/Quality-Initiatives-Patient-Assessment-Instruments/HomeHealthQualityInits/index.html. Accessed January 25, 2019.

59. Joynt Maddox KE, Chen LM, Zuckerman R, Epstein AM. Association Between Race, Neighborhood, and Medicaid Enrollment and Outcomes in Medicare Home Health Care. J Am Geriatr Soc. 2018;66(2):239-246.

60. Cook A. In Value-Based Payment, the Direct Care Workforce Matters 2019; https://phinational.org/in-value-based-payment-the-direct-careworkforce-matters/.

Publisher's Note Springer Nature remains neutral with regard to jurisdictional claims in published maps and institutional affiliations. 